\title{
The Burgeoning Covid-19 Waste is Hurting the Environment: Reuse of PPE
}

\section{Sharma P* \\ Chandigarh Unit of Association of Microbiologists, Punjab University, India}

*Corresponding author: Prince Sharma, Dean, President, Faculty of Science, Chandigarh Unit of Association of Microbiologists of India, Punjab University, Chandigarh, India, Email: princess@pu.ac.in

\section{Opinion}

The world has already committed blunders in accumulating millions of tons of plastic in the planet, much of which has gone into oceans as micro plastic destroying the eco-system and marine life and the biodiversity enlarge.

The unprecedented Covid-19 times have mandated PPEs for health workers and masks for everyone. This has started generating heaps of PPE waste. In Chandigarh city alone nearly 40,000 kg of biomedical waste (including PPE) is generated every month. Where does this PPE waste go? Much to incinerators. Lots of it is reaching landfills and illiterate public throws it (masks) everywhere.

The disposable surgical (medical) masks and N95 respirators and surgical gowns are made of nonbiodegradable polypropylene or polystyrene or polyethylene material. The face shield and goggles are made from polycarbonate/acrylic. Their single use generates tons of waste everyday which is becoming an environment hazard, like plastic.

Reuse, recycle and reduce are the mantras for protection of eco-system from environment degrading material. Much of the attention has been given to reuse of PPE and recycling where possible. While readying the disposed of PPE for reuse, care has to be taken for (i) proper decontamination of pathogen and its validation (ii) causing no change in filtering and material properties and (ii) causing no deformity e.g. in N95 fit properties. Methods which can meet these requirements for reuse will be welcome. Ordinary methods like washing with detergent or alcohol or sanitizers or bleach are failures.
Department of Microbiology, Panjabi University, Chandigarh, INDIA, has initiated a research work on developing such methods for reuse where decontamination of pathogen and its validation will be done. Methods like mild heat, UV irradiation and mild chemicals e.g. $\mathrm{H}_{2} \mathrm{O}_{2}$ vapors for treating used masks, respirators, face shield, gowns so as to reuse them, are being tested.

The Chandigarh Unit of Association of Microbiologists of India is promoting, by public awareness, the reuse of PPE wherever possible as it is a matter of environment concern and safety, besides being economical. It recommends the use of DIY multilayered cotton masks by general public as these are washable and reusable (Figures 1 \& 2).

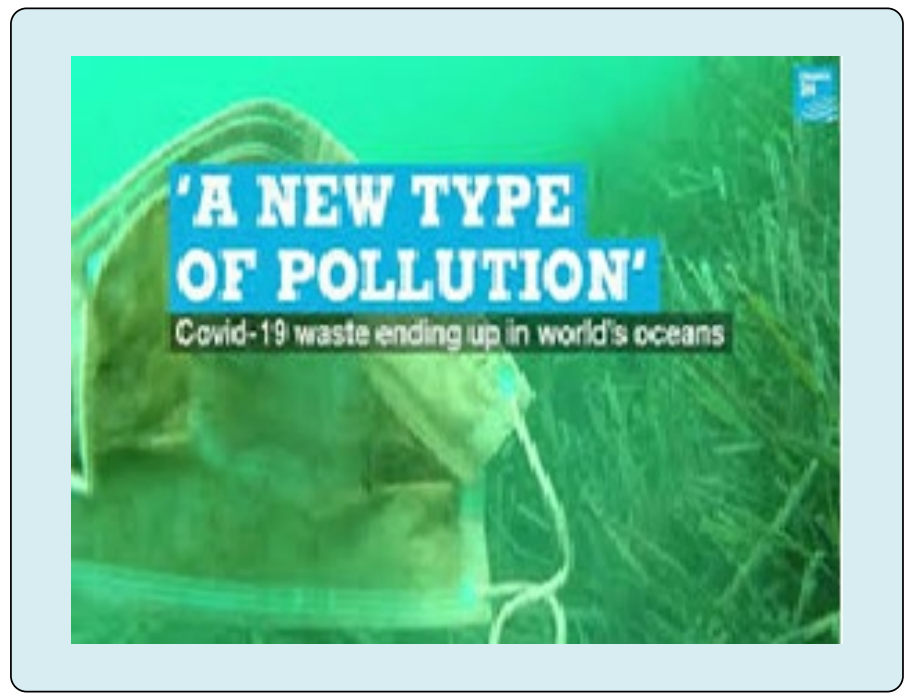




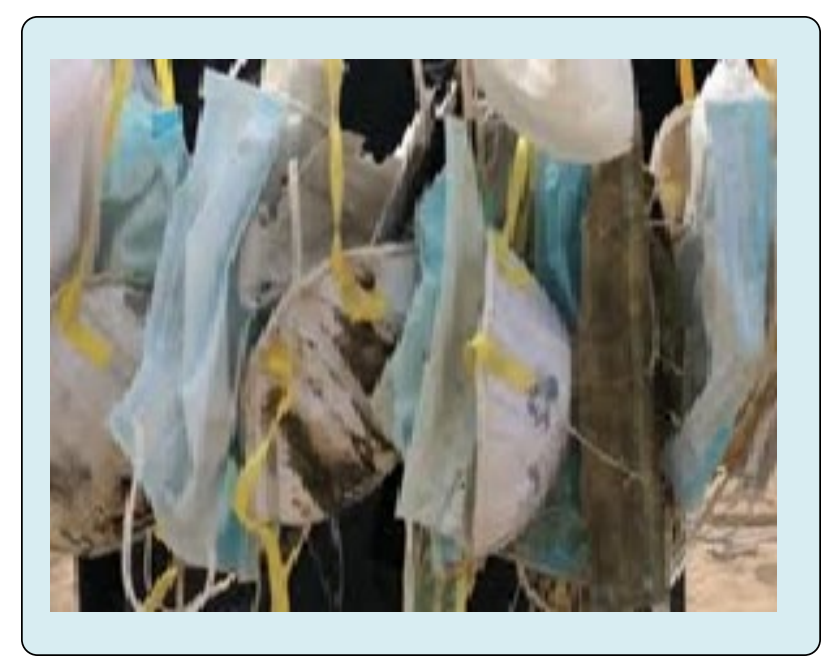

*Saving Environment*

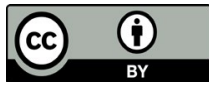

